EGU21-7687, updated on 25 May 2021

https://doi.org/10.5194/egusphere-egu21-7687

EGU General Assembly 2021

(c) Author(s) 2021. This work is distributed under

the Creative Commons Attribution 4.0 License.

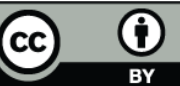

\title{
Two-Phase Flow in Rough Fractures - Insights from 3D-Printed Fractures
}

\author{
Tomos Phillips ${ }^{1,2}$, Jeroen Van Stappen ${ }^{2}$, Tom Bultreys ${ }^{2}$, Stefanie Van Offenwert ${ }^{2}$, Arjen Mascini ${ }^{2}$, \\ Shan Wang ${ }^{2}$, Veerle Cnudde ${ }^{2,3}$, and Andreas Busch ${ }^{1}$ \\ ${ }^{1}$ Institute of GeoEnergy Engineering, Heriot-Watt University, The Lyell Centre, Edinburgh, UK \\ ${ }^{2}$ Department of Geology, PProGRess/UGCT, Ghent University, Belgium \\ ${ }^{3}$ Department of Earth Sciences, Utrecht University, Utrecht, The Netherlands
}

Fractures can provide principal fluid flow pathways in the Earth's crust, making them a critical feature influencing subsurface geoenergy applications, such as the storage of anthropogenic waste, emissions or energy. In such scenarios, fluid-conductive fault and fracture networks are synonymous with two-phase flow, due to the injection of an additional fluid (e.g. $\mathrm{CO}_{2}$ ) into an already saturated (e.g. brine) system. Predicting and modelling the resulting (partly-)immiscible fluid-fluid interactions, and the nature of fluid flow, on the field-scale, requires an understanding of the constitutive relationships (e.g. relative permeability and capillary pressure) governing fluid flow on the single-fracture scale. In addition to capillary and viscous forces, fracture relative permeability is influenced by aperture heterogeneity, arising from surface roughness. The degree to which surface roughness controls relative permeability behaviour in fractures remains unclear. As all fractures display roughness to various degrees, furthering our understanding of two-phase flow in fractures benefits from a systematic investigation into the impact of roughness on flow properties. To this end, we performed co-injection experiments on two 3D-printed (polymeric resin) fractures with different controlled and quantified surface roughness distributions (Joint Roughness Coefficients of $5 \& 7$ ). Brine and decane were simultaneously injected at a series of incrementally decreasing brine fractional flow rates $(1,0.75,0.5,0.25$, and 0$)$, at low total volumetric flow rates $(0.015 \mathrm{~mL} / \mathrm{min})$. Steady-state fluid occupancy patterns, preferential flow pathways and overall fluid saturations in each fracture were imaged and compared using an environmental laboratory-based $\mu$-CT scanner with a $5.8 \mu \mathrm{m}$ voxel size (EMCT; Ghent University Centre for X-ray Computed Tomography). Experimental results highlight the importance of roughness on the relative permeability behaviour of fractures, which is, for example, a principal control on leakage rates from geological stores. 